\title{
Resenha do livro:
}

\section{GOFFMAN, Erving. Manicômios, Prisões e Conventos. Tradução de Dante Moreira Leite. $7^{\text {a }}$ edição. São Paulo: Editora Perspectiva, 2001.}

\author{
Resenha por Nádia Cuiabano Kunze \\ Centro Federal de Educação Tecnológica de Mato Grosso - CEFETMT \\ nkunze@usp.br
}

\section{Instituições Totais}

Erving Goffman, professor do Departamento de Sociologia da Universidade da Califórnia em Berkely - EUA e cientista social, foi membro visitante do Laboratório de Estudos Sócio-Ambientais do Instituto Nacional de Saúde em Bethesda, Maryland/EUA, entre os anos de 1954 e 1957, quando desenvolveu estudos sobre o comportamento em enfermarias nos Institutos Nacionais do Centro Clínico de Saúde. No período de 1955 a 1956, efetuou um trabalho de campo no Hospital St. Elizabets, instituição federal com cerca de 7.000 internos, em Washington, objetivando conhecer o mundo social do interno em hospital para doentes mentais a partir de uma análise sociológica da estrutura do eu que utilizou como método de obtenção de dados etnográficos a sua inserção no mundo dos internos, na condição de auxiliar observador, sem utilizar medidas de controles.

Os resultados desse estudo que o permitiram formular os conceitos de "instituição total", de "carreira moral", de "vida íntima da instituição" e analisar o modelo médico e a hospitalização psiquiátrica, são apresentados em quatro artigos nesta obra.

No $1^{\circ}$ artigo (As características das instituições totais), o autor vai indicar que certos mecanismos de estruturação de uma instituição determinam a sua condição de instituição total e acarretam conseqüências na formação do eu do indivíduo que nela participa sob determinada condição.

Para Goffman, o ser age nas esferas da vida em diferentes lugares, com diferentes co-participantes e sob diferentes autoridades sem um plano racional geral, ao inserir-se numa instituição social passa a agir num mesmo lugar, com um mesmo grupo de pessoas e sob tratamento, obrigações e regras iguais para a realização de atividades impostas. Quando essa instituição social se organiza de modo a atender indivíduos (internados) em situações semelhantes, separando-os da sociedade mais ampla por um período de tempo e impondo-lhes uma vida fechada sob uma administração rigorosamente formal (equipe dirigente) que se baseia no discurso de atendimento aos objetivos institucionais, ela apresenta a tendência de "fechamento" o que vai simbolizar o seu caráter "total".

Esse caráter total da instituição age sob o internado de maneira que o seu eu passa por transformações dramáticas do ponto de vista pessoal e do seu papel social. O autor afirma que esse fato pôde ser ricamente verificado no hospital para doentes mentais e, para esclarecê-lo bem, detalha o processo que o desencadeia descrevendo "o mundo do internado". Quando o internado chega ao hospital ele sofre um processo de "mortificação do eu" que suprime a "concepção de si mesmo" e a "cultura aparente" que traz consigo, que são formadas na vida familiar e civil e não são aceitas pela sociedade. Estes "ataques ao eu" decorrem do "despojamento" do seu papel na vida civil pela imposição de barreiras no contato com o mundo externo, do "enquadramento" pela imposição das regras de conduta, do "despojamento de bens" que o faz perder seu conjunto de identidade e segurança pessoal, e da "exposição contaminadora" através de elaboração de um dossiê 
que viola a reserva de informação sobre o seu eu "doente". Esse mecanismo, além de causar a perturbação da relação entre ator/indivíduo e seus atos, causa o "desequilíbrio do eu", uma vez que profana as ações, a autonomia e a liberdade de ação do internado.

A esse momento, concomitantemente, ocorrem os mecanismos de reorganização pessoal que representam instruções formais e informais de reestruturação do eu e que garantem um sistema de privilégios. As regras da casa, rotinas diárias, são um conjunto de prescrições e proibições que, se bem aceitas, permitem prêmios e privilégios ou, se desobedecidas, geram o castigo, quer dizer, suspensão temporária ou permanente dos privilégios. Goffman salienta que as noções de privilégios na instituição total não são retiradas do padrão da vida civil, não são considerados como favores e sim como a ausência da privação.

Diante da influência reorganizadora o internado passa a desenvolver a sua adaptação que pode se dar pelos "ajustamentos primários", quando contribui cooperativamente com as atividades exigidas pela instituição, ou pelos "ajustamentos secundários", quando empregam meios ilícitos ou não autorizados para obterem satisfações proibidas, escapando do que a organização supõe que deve fazer ou obter, ou seja, escapando daquilo que deve ser.

As "táticas de adaptação", que significam as respostas que o internado dá às regras da casa, ocorrem a partir de ajustamentos primários, secundários ou da combinação destes em diferentes fases da sua vida de paciente e são classificadas por Goffman como "afastamento da situação" - desatenção e abstenção aos acontecimentos de interações, "intransigência" - não cooperação e desafio à instituição, "colonização" - consideração da vida institucional como desejável em relação às experiências ruins no mundo externo, "conversão" - aceitação da interpretação oficial e representação do papel de internado perfeito, "viração" - combinação de várias táticas visando evitar sofrimentos físicos e psicológicos - e "imunização" - o mundo da instituição passa a ser um mundo habitual sem novidades.

Esses mecanismos de mortificação do eu e de reorganização pessoal geram um ambiente cultural que causa no internado a sensação de fracasso, um sentimento de que o tempo de internação é perdido, mas que precisa ser cumprido e esquecido e uma angústia diante da idéia de retorno à sociedade externa. Essa angústia decorre do "status proativo" o internado se vê diante de uma nova posição social que é diversa da anterior que, por sua vez, não será a mesma quando sair do hospital, e do "desculturamento" - o internado se vê diante da impossibilidade de adquirir os hábitos atuais que a sociedade passará a exigir.

$\mathrm{O}$ autor preocupou-se em caracterizar o hospital psiquiátrico como instituição total com o rico detalhamento do mundo do internado, porém não deixa de apresentar o caráter total da instituição do ponto de vista do mundo da equipe dirigente. Neste, a organização formal convive com uma contradição latente: o que a instituição faz e aquilo que deve dizer que faz. Para superá-la arma o "esquema de interpretação" que inicia quando: a) o internado é admitido e a equipe dirigente o define como o tipo de pessoa que a instituição objetiva "tratar", b) a equipe dirigente procura encontrar um tipo de comportamento que se ajuste às regras da casa que são apresentadas como o objetivo legítimo da instituição, e c) o internado é levado a apresentar condutas controladas. Nesse mundo, a equipe dirigente precisa impor obediência ao internado, precisa dar a impressão de que os padrões humanitários são mantidos e de que os objetivos racionais da instituição estão sendo realizados.

Parece-nos, à primeira impressão, que as duas esferas - internados e equipe dirigentes - mantém uma distância social e têm somente uma interação limitada aos "padrões de deferências" que são impostos formalmente com exigências específicas e 
sanções para as infrações e que devem ser apresentados pelo internado à equipe dirigente obedecendo a escala dos papéis. No entanto, ocorrem relações/ligações entre ambas de forma ilícita e pessoal ou solidária quando existe um compromisso conjunto em relação à instituição, na execução, respectivamente, da rotina da instituição e de certas atividades que Goffman denomina "cerimônias institucionais". Estas cerimônias, festa anual, confecção de jornal ou revista, esportes internos, cerimônias religiosas e exibição institucional (teatro, música, ...), são vistas como a possibilidade do internado reaprender a viver em sociedade e reaprender a capacidade e voluntariedade para realizar tal vivência. Nelas, a equipe dirigente representa mais que um papel de supervisão, por isso, podem ocorrer influências mútuas entre os padrões sociais de um e de outro, principalmente quando são provenientes da mesma classe social na comunidade externa. O grau dessas influências - "permeabilidade" - tem como conseqüência a redução das diferenças, a geração da comunicação e a dificuldade da manutenção da distância intragrupo. Para que a manutenção da moral, da instabilidade e dos objetivos da instituição seja garantida a equipe dirigente utiliza a "impermeabilidade" - negação das influências - com o discurso de ruptura com o passado e supressão das distinções sociais externas do internado dando um caráter democrático ao seu tratamento.

No $2^{\circ}$ artigo (A carreira moral do doente mental), é apresentada a seqüência padronizada das mudanças na concepção do eu do internado que o autor denomina como "carreira moral" do doente mental, a qual é entendida a partir de um sentido sociológico que considera a imagem e as fases do internado no complexo institucional.

O início social da carreira moral do paciente mental se dá quando ocorre a denúncia de sua transgressão que vai gerar a sua hospitalização. A fase de pré-paciente inicia com a sua inserção na instituição, através da internação voluntária ou involuntária, e, a partir daí, sofre a expropriação de suas relações e direitos com o mundo externo. Um circuito de agentes - a pessoa mais próxima (membro da família), o denunciante da transgressão (membro da família ou amigos) e os mediadores (médico, polícia, ...) - atua sobre o seu eu causando a "coalização alienadora" - sentimento de traição/enganação em relação à pessoa mais próxima e ao denunciante da transgressão - e a "a cerimônia de degradação" - a ofensa causada pela pessoa mais próxima que se torna um fato social público por envolver outra pessoa, no caso os mediadores. Em seguida, esta fase culmina com a "construção histórica do caso", pelos mediadores, que tem um caráter retrospectivo do passado do internado.

$\mathrm{Na}$ "fase de internado" o paciente, num primeiro momento, desenvolve um sentimento de abandono, um desejo de anonimato e os contatos são evitados. Num segundo momento, ocorre a "aceitação" quando percebe que foi despojado de suas defesas, satisfações e afirmações e informa-se de que as restrições e privações são partes intencionais do tratamento para sua cura - já se vê com o status de pessoa - e aprende a orientar-se no sistema hospitalar. Num terceiro momento, apresenta apologia do seu eu criando "histórias tristes" que explicam o fracasso do passado e apresenta tendência de auto-respeito com o reforço da ficção. Goffman chama a atenção para o fenômeno de negação da racionalidade do paciente que ocorre, nesse momento, quando a equipe dirigente desmente as histórias tristes com as informações contidas no seu dossiê e, conseqüentemente, ele passa a ter que aceitar ou fingir aceitar a interpretação do hospital. Num quarto momento, mesmo sendo verdadeiros os registros, o paciente procura escondêlos, sente-se ameaçado por estarem disponíveis e não poder controlá-los e se vê obrigado a reconstruir sua história que tende a ser desmentida novamente. Enfim, aprende a viver sob as condições de eminentes exposições e apresenta a "fadiga moral" quando aprende que pode sobreviver, mesmo agindo de uma forma que a sociedade considera destrutiva. 
No $3^{\circ}$ artigo (A vida íntima de uma instituição pública), o autor esclarece que o ser participa de uma organização cumprindo as obrigações que lhes são apresentadas e que delineiam padrões de bem estar, valores, incentivos e sanções - suposições a respeito do eu.

A participação do indivíduo diante das obrigações institucionais ocorre via ajustamentos primários e secundários e o conjunto desses ajustamentos é o que Goffman considera, aqui, como "vida íntima da instituição". No estudo da vida íntima de uma instituição total, no caso um hospital psiquiátrico, deteve-se à analise dos ajustamentos secundários que nela se desenvolvem por demonstrarem que, de alguma forma, os participantes se recusam a aceitar a sua interpretação oficial do que devem dar e retirar dela e do tipo de mundo que devem aceitar para si mesmos.

Esclarece que na vida íntima de um hospital psiquiátrico os pacientes empregam um sistema de ajustamentos secundários que utiliza: a) como fontes, as "substituições" (utilização de coisas disponíveis que modificam as condições de vida programadas), e a "exploração do sistema" (as rotinas oficiais são utilizadas para fins particulares e que podem ocorrer individual ou coletivamente); b) como locais, os "espaços fora de alcance" (proibidos), os "espaços de vigilância" (permitidos com controle), os "espaços não regularizados" (sem controle), os "locais livres" (com vigilância e restrições reduzidas), os "territórios de grupos" (locais livres com comando de determinado grupo de paciente), e o "território pessoal" (espaço íntimo criado no interior de um local livre ou território de grupo); e c) como recursos, os "esconderijos" portáteis ou fixos (usados para esconder bens adquiridos legitimamente nos ajustamentos primários), o "sistema de transporte" (transporte dos bens ao esconderijo), e o "sistema de comunicação" (circulação de mensagens, comunicação oculta (expressões), comunicação mediada (sistema oficial de informação), mensageiro (paciente)).

Goffman salienta que esses mecanismos são utilizados nos ajustamentos secundários via organização de uma estrutura social para esse fim, na qual ocorre o "uso do outro" - ajuste regular dos esforços, serviços e bens de um paciente aos planos pessoais de um outro para o aumento da amplitude de seus ajustamentos secundários. O esforço alheio é incorporado por meio de "coerção particular" (o coagido obedece involuntariamente), de "intercâmbio econômico" (o outro contribui pela venda ou barganha dos seus esforços e serviços), e de "intercâmbio social" (o outro contribui em troca de coisas afetuosamente desejadas ou de um gesto cerimonial através de relações particulares extra-oficiais, relações pessoais estabelecidas ou relações de proteção oficiais).

Um ponto que precisa ficar claro, e que o autor expõe muito bem neste artigo, é que a prática dos ajustamentos secundários ocorre com determinações múltiplas seja por desprezo e malícia, ou porque é proibida, porque é fonte de prazer, ou, por adesão contra o poder da instituição, e significam para o praticante que ele tem individualidade e autonomia pessoal que não estão ao alcance da organização, o que permite a preservação do seu eu. Já para a doutrina psiquiátrica, as ações que o paciente é levado a fazer é parte do tratamento ou custódia e são entendidas como sintomas da doença/perturbação.

No $4^{\circ}$ artigo (O modelo médico e a hospitalização psiquiátrica), Goffman apresenta a justificativa do porque a ação de um hospital psiquiátrico sob os pacientes é legitimada e aceita pela sociedade. Para ele, os indivíduos se aproximam de maneiras diferentes visando o estabelecimento de interações, e que uma das mais importantes é a de servidor (profissional) versus servido (cliente), na qual se apresenta uma relação de serviço.

No caso de um hospital médico a interação ocorre a partir do momento em que uma pessoa (cliente) busca um médico (profissional) para curar-lhe uma doença, acreditando que este seja o único com competência para tanto. Pela "parte técnica" (relato das 
dificuldades pelo paciente e observações das dificuldades pelo profissional), o médico recebe as informações dos sintomas e sinais da doença e, pela "operação mecânica" (atitudes de reparos), propicia a cura da doença. Neste caso as incapacidades físicas necessitam de tratamento para o bem estar da pessoa.

No caso de um hospital psiquiátrico, as atividades nele realizadas são disfarçadas como um "esquema de serviço médico", acima descrito, e é por isso que se legitimam. Do ponto de vista da instituição, o psiquiatra deve oferecer seus serviços porque o doente mental clama, voluntária ou involuntariamente, por tratamento. As queixas do paciente referentes à instituição e os seus ajustamentos secundários devem ser considerados por ele, respectivamente, como sintomas e sinais da sua perturbação e que devem ser compreendidas pelo primeiro como o reconhecimento da sua doença. O tratamento que deve prescrever sob a forma de "arregimentação" (dormitório, cela de isolamento, controle de impulsos, remédios, tarefas, prêmios e castigos), deve ser considerado como um mecanismo de reparo de um eu doente.

Finalmente, é importante destacar que, ao apresentar esses aspectos da profissão do médico psiquiatra, Goffman nos faz refletir sobre a "ideologia institucional" que ele precisa defender, mesmo não aceitando-a. Precisa ver como patologia o que a sociedade vê como mau comportamento, precisa considerar que a patologia necessita de tratamento porque significa a incapacidade e despreparo do paciente para viver em comunidade, precisa ver que o sucesso da "cura" é fruto de um trabalho eficaz do hospital e que o fracasso da mesma é devido ao caráter rebelde da perturbação.

A maior contribuição que esta obra pode oferecer ao leitor é a possibilidade de aproximação à rotina das instituições de reclusão e de construção de um outro olhar sobre elas e seus participantes. Apesar de tratar da especificidade de um hospital psiquiátrico, o autor elaborou certos conceitos sobre sua dinâmica que também podem ser utilizados em análises sobre outros tipos de instituição com tendência de fechamento como: prisões, conventos, internatos escolares, entre outros. 
INSTITUIÇÕES TOTAIS DE ERVING GOFFMAN

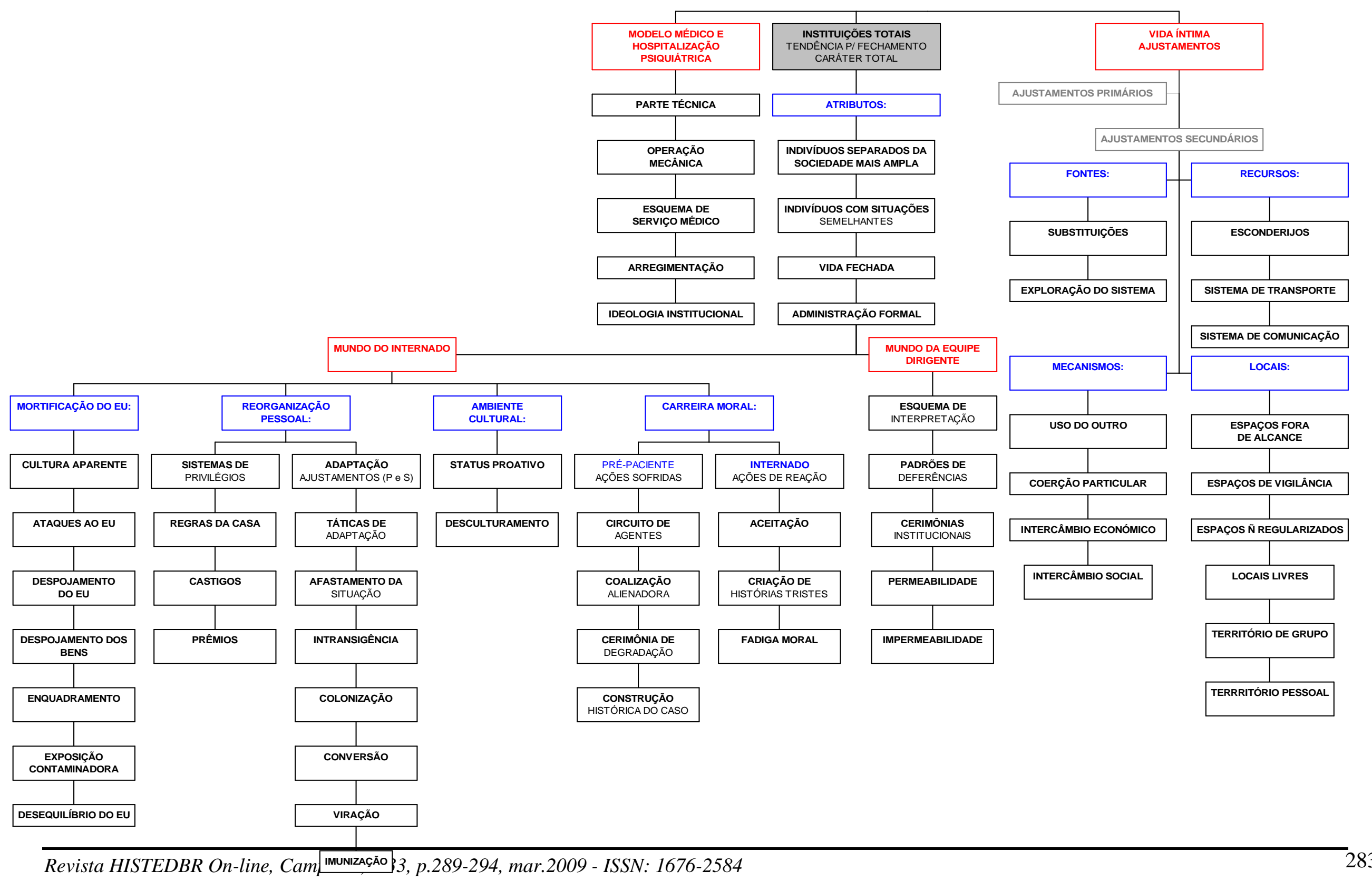

